\title{
Den andra kända observationen av polygyni hos ortolansparv Emberiza hortulana
}

\author{
Second known record of polygyny in Ortolan Bunting Emberiza hortulana
}

\author{
MAGNUS PERSSON \& JAN SONDELL
}

\begin{abstract}
During field work on foraging of the Ortolan Bunting Emberiza hortulana in a small and isolated population at Kvismaren in the county of Örebro in south Sweden, two females, nesting $1250 \mathrm{~m}$ apart were observed to be mate-guarded by the same colour-ringed male. Although the male commuted between the nests, none of the females seemed to obtain any substantial help from him when feeding the young. Polygyni has been reported only once before in this species, namely seventy-five years

\author{
ago, also in a small population in Sweden, when a male \\ behaved in a similar manner to that that we observed at \\ Kvismaren. \\ Magnus Persson, Husön, 71592 St Mellösa, Sweden. \\ Email: humlapersson@gmail.com \\ Jan Sondell, Rulleuddsvägen 10, S-178 51 Ekerö, Sweden. \\ Email: jan.sondell@telia.com
}

Received 6 September 2018, Accepted 2 October 2018, Editor: Sören Svensson

Den 2 maj 2017 upptäcktes en nyanländ hanne av ortolansparv Emberiza hortulana i en björkholme på slätten nordost om Sörön i Kvismaren (Anderssons holme). Den 3 maj sjöng samma individ vid Lindåsabacken ytterligare ca $500 \mathrm{~m}$ mot öster. Ungefärlig koordinat är 59 $11^{\circ} ; 15^{\circ} 26^{\prime}$. Det var en gammal färgmärkt hanne som funnits på platsen flera år. År 2015 konstaterades den häcka i just Anderssons holme. Den observerades även 2016. Parningsförsök noterades den 16 maj 2017 vid Lindåsabacken och paret visade sig sedermera häcka där. I samband med ett projekt 2017 angående ortolansparvens födosök (Sondell et al. in press) följdes Lindåsa-paret, som hade bo i gräsmark nedanför en stor ek, kontinuerligt ända tills ungarna lämnade boet. För att undvika störning letades dock inte den exakta boplatsen upp utan vi nöjde oss med iakttagelser av var de matande fåglarna landade i gräset. (En sen parning noterades även 12 juni då det fanns ungar i boet.)

I Kvismaren fanns 2017 öster om Sörön fem stycken bon av ortolansparv som alla detaljstuderades av personal från Kvismare fågelstation. En hanne hördes sjunga intensivt vid norra delen av Sörön den 20 maj. Den 25 maj observerades en hona bygga bo på samma plats och en av oss (MP) följde honans bobyggnad i kanten av ett dike intill Sörön. Vid bobyggnaden bevakade den färgmärkta hannen honan genom att följa efter henne några meter ovanför när hon samlade grässtrån från marken. Den individmärkta hannen hade vid Sörön samma färgkombination som hannen vid Lindåsabacken. Parning iakttogs vid Sörön den 29 maj ca $25 \mathrm{~m}$ från boet och 30 minuter efter parningen flög hannen bort till boet vid Lindåsabacken. Inga andra oidentifierade hannar sågs vid Sörön.

Vad som starkt styrker att den färgmärkta hannen var far till ungarna $i$ båda bona var att hannen vid Lindåsabacken sågs flyga iväg mot norra Sörön vid minst fyra tillfällen och han sågs även minst en gång flyga i motsatt riktning (som nämnts ovan).

I Söröboet, som kunde besökas utan större störningsrisk eftersom det låg skyddat $\mathrm{i}$ dikeskanten fanns två ungar. Honan till detta bo sökte som längst föda på ca 150 meters avstånd från sitt bo $\mathrm{i}$ riktning mot Lindåsaboet. Vi beräknar att ungarna vid Lindåsabacken kläcktes 6 juni och ungarna vid Sörön 16 juni, en skillnad på ca 10 dagar. Avståndet mellan bona var $1250 \mathrm{~m}$.

I Tabell 1 redovisas antalet observerade matningar av respektive kön för samtliga fem bon som hölls under observation 2017. Så vitt vi kunde observera hjälpte den polygyna hannen i liten utsträckning till med uppfödningen av ungarna i boet vid Sörön (han stod för bara $8 \%$ av de matningar där könet kunde bestämmas). Hans bidrag till matningen vid Lindåsaboet var något större $(13 \%$ av matningarna av könsbestämd fågel). Om de polygama bona läggs ihop är matningen lika frekvent som för de monogama hanarna i bo 2 och 3. (För bo 1 finns bara få observationer.) De svarade för ungefär en femtedel av matningarna. 
Table 1. Antal bobesök med föda till ungarna och hannens andel (\%) av besöken för tre bon av ortolansparv med monogam hane och två bon med en polygyn hane.

Number of nest visits with food for the young and the male's share (\%) of the visits for three nests of Ortolan Bunting with monogamous males and two nests with a polygynous male.

\begin{tabular}{|c|c|c|c|c|c|}
\hline & $\begin{array}{l}\text { Hane } \\
\text { Male }\end{array}$ & $\begin{array}{r}\text { Hona } \\
\text { Female } \\
\end{array}$ & $\begin{array}{r}\text { Okänt kön } \\
\text { Unknown sex }\end{array}$ & $\begin{array}{l}\text { Summa, känt kön } \\
\text { Total, known sex }\end{array}$ & $\begin{array}{l}\% \text { av hanen } \\
\% \text { by male }\end{array}$ \\
\hline \multicolumn{6}{|l|}{ Monogama hanar } \\
\hline 1 Andersson N & 6 & 5 & 17 & 11 & 55 \\
\hline 2 Andersson $\mathrm{S}$ & 9 & 37 & 7 & 46 & 20 \\
\hline 3 Andersson W & 4 & 14 & 3 & 18 & 22 \\
\hline Summa Total & 19 & 56 & 27 & 75 & 25 \\
\hline \multicolumn{6}{|l|}{ Polygyn hane } \\
\hline 4 Lindåsa & 10 & 69 & 41 & 79 & 13 \\
\hline 5 Sörön & 4 & 45 & 0 & 49 & 8 \\
\hline Summa Total & 14 & 114 & 41 & 128 & 11 \\
\hline
\end{tabular}

Eftersom vi inte kände till något fall av polygyni hos ortolansparven gick vi igenom några av de större handböckerna (Rosenius 1926, Glutz von Blotzheim 1997 och Cramp \& Perrins 1974). I de två senare fann vi en enda och samma referens, nämligen till Durango (1948). Denne beskrev "une petite colonie" av ortolansparv i Uppland med två hannar och tre honor. Det var två reguljära par under häckningen men han såg också att en av de parade hannarna eskorterade den tredje honan flera gånger. Han hjälpte henne dock inte med matning av ungar. "Den var säkert polygam" konstaterar Durango. Detta beteende stämmer väl med hur vi uppfattade den polygama hannens uppträdande i Kvismaren 75 år senare. Som Durango påpekar är polygami vanligt hos släktingen kornsparv.
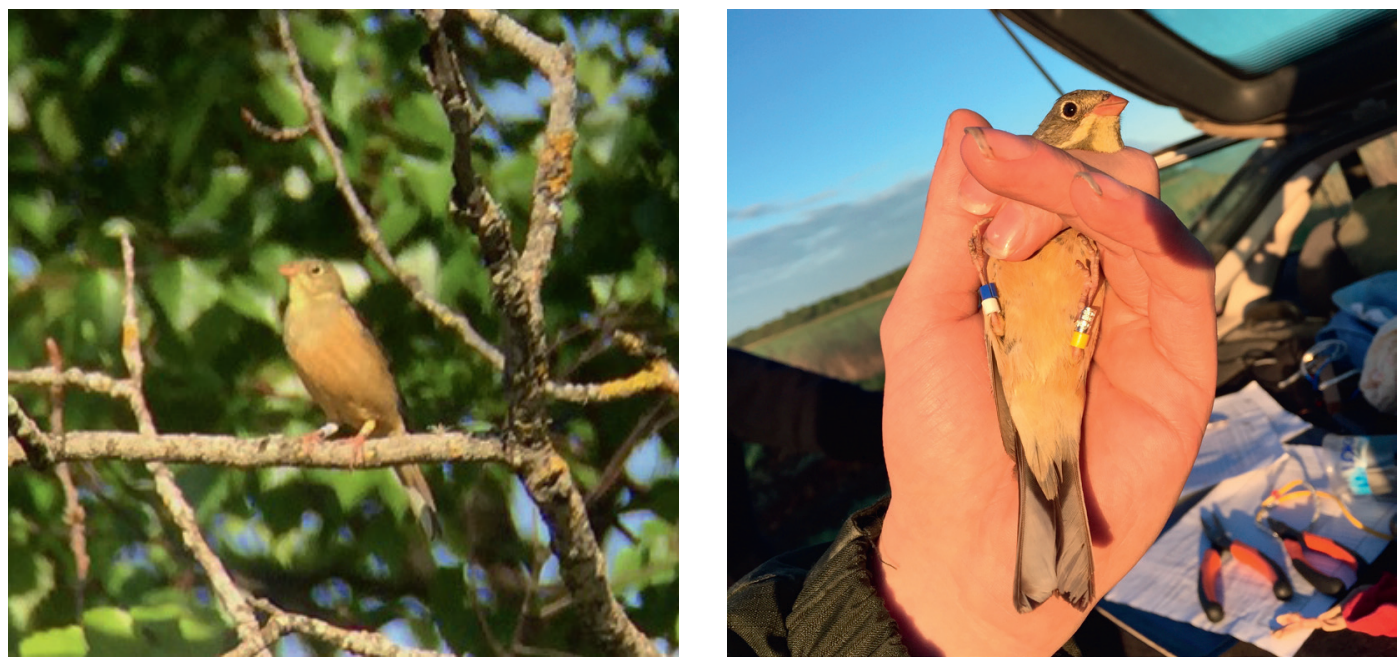

Hanen av ortolansparv som hade två honor med bo 1250 meter från varandra vid Sörön och Lindåsa i Kvismaren 2017. Foto: Magnus Persson.

The male Ortolan Bunting who hade two females with nests 1250 metres apart at Sörön and Lindåsa at Kvismaren 2017. 


\section{Tack}

Vi tackar de fyra personer från Kvismare fågelstation som 2017 medverkade i studierna av ortolanernas födosök och som under en månads tid dagligen bevakade ortolanernas boplatser och aktiviteter. Länsstyrelsen i Örebro tackas också för ekonomiskt bidrag till projektet. Denna rapport är Meddelande nr 189 från Kvismare fågelstation.

\section{Referenser}

Cramp, S. \& Perrins, C.M. 1974.The Birds of the Western Palearctic. Vol 9. Oxford Univ. Press.

Durango, S. 1948. Notes sur la reproduction du bruant ortolan en Suéde. Alauda 14: 1-21.

Glutz von Blotzheim, U.N. 1997. Handbuch der Vögel Mitteleuropas.

Rosenius, P. 1926. Sveriges fåglar och fågelbon. Gleerups, Lund.

Sondell, J., Dura, C. \& Persson, M. Breeding prerequisites for Ortolan Bunting (Emberiza hortulana) in Swedish farmland with special focus on foraging. Ornis Svecica, in press.

\section{Summary}

During studies of foraging and foraging habitats of a small Ortolan Bunting population counting five nests at Kvismaren, central Sweden, we found that one of the males attended two of the females. The male was colour-ringed and the nests were 1250 $\mathrm{km}$ apart so there is no doubt about the reliability of the observation. The male was observed to be mate-guarding the females several times. The first nest hatched about 6 June and the second 10 days later; around 16 June.

Table 1 shows the number of feeding trips that were recorded for the different sexes in all five nests. The polygynous male provided only half as many visits with food to each of his mates comparted with the monogamous males, but his total effort for both his broods was about the same.

We have found only one earlier reported observation of polygyny among Ortolan Buntings, also originating from Sweden, 75 years ago (Durango 1948). The situation was similar to the Kvismaren case with a small population where the male was observed accompanying also a second female. 